\title{
The global Landsat archive: Status, consolidation, and direction
}

Michael A. Wulder*, Joanne C. White, Thomas R. Loveland, Curtis E. Woodcock, Alan S. Belward, Warren B. Cohen, Eugene A. Fosnight, Jerad Shaw, Jeffrey G. Masek, and David P. Roy

Wulder, White: Canadian Forest Service, (Pacific Forestry Center), Natural Resources Canada, 506 West Burnside Road, Victoria, BC, V8Z 1M5, Canada

Loveland, Fosnight: U.S. Geological Survey Earth Resources Observation and Science (EROS) Center 47914 252nd Street, Sioux Falls, SD 57198, USA

Woodcock: Department of Earth and Environment, Boston University, MA 02215, USA

Belward: European Commission, Joint Research Centre, Institute for Environment and Sustainability, 20133 VA, Italy

Cohen: Forestry Sciences Laboratory, USDA Forest Service, Corvallis, OR, 97331, USA

Shaw: Stinger Ghaffarian Technologies (SGT), Earth Resources Observation and Science (EROS) Center 47914 252nd Street, Sioux Falls, SD 57198, USA

Masek: Biospheric Sciences Laboratory, NASA Goddard Space Flight Center, Greenbelt, MD 20771, USA

Roy: Geospatial Sciences Center of Excellence, South Dakota State University, Brookings, SD 57007, USA

*Corresponding author. Mike Wulder, 250-298-2401; mike.wulder@ canada.ca

Submitted to: Remote Sensing of Environment, Landsat-8 Special Issue

Key words: Landsat Global Archive Consolidation, LGAC, satellite, monitoring, Landsat

(C) 2015. This manuscript version is made available under the Elsevier user license http://www.elsevier.com/open-access/userlicense/1.0/ 


\section{Abstract}

New and previously unimaginable Landsat applications have been fostered by a policy change in 2008 that made analysis-ready Landsat data free and open access. Since 1972, Landsat has been collecting images of the Earth, with the early years of the program constrained by onboard satellite and ground systems, as well as limitations across the range of required computing, networking, and storage capabilities. Rather than robust on-satellite storage for transmission via high bandwidth downlink to a centralized storage and distribution facility as with Landsat-8, a network of receiving stations, one operated by the U.S. government, the other operated by a community of International Cooperators (ICs), were utilized. ICs paid a fee for the right to receive and distribute Landsat data and over time, more Landsat data was held outside the archive of the United State Geological Survey (USGS) than was held inside, much of it unique. Recognizing the critical value of these data, the USGS began a Landsat Global Archive Consolidation (LGAC) initiative in 2010 to bring these data into a single, universally accessible, centralized global archive, housed at the Earth Resources Observation and Science (EROS) Center in Sioux Falls, South Dakota. The primary LGAC goals are to inventory the data held by ICs, acquire the data, and ingest and apply standard ground station processing to generate an L1T analysis-ready product. As of January 1, 2015 there were 5,532,454 images in the USGS archive. LGAC has contributed approximately 3.2 million of those images, more than doubling the original USGS archive holdings. Moreover, an additional 2.3 million images have been identified to date through the LGAC initiative and are in the process of being added to the archive.. The impact of LGAC is significant and, in terms of images in the collection, analogous to that of having had two additional Landsat-5 missions. As a result of LGAC, there are regions of the globe that now have markedly improved Landsat data coverage, resulting in an enhanced capacity for mapping, monitoring change, and capturing historic conditions. Although future missions can be planned and implemented, the past cannot be revisited, underscoring the value and enhanced significance of historical Landsat data and the LGAC initiative. The aim of this paper is to report the current status of the global USGS Landsat archive, document the existing and anticipated contributions of LGAC to the archive, and characterize the current acquisitions of Landsat-7 and Landsat- 
8. Landsat- 8 is adding data to the archive at an unprecedented rate as nearly all terrestrial images are now collected. We also offer key lessons learned so far from the LGAC initiative, plus insights regarding other critical elements of the Landsat program looking forward, such as acquisition, continuity, temporal revisit, and the importance of continuing to operationalize the Landsat program.

\section{Introduction}

Following the opening of the Landsat archive in 2008 (Woodcock et al. 2008), interest around and use of Landsat imagery has increased dramatically (Wulder et al. 2012; Roy et al. 2014). Users need to know what is in the archive, how the archive was and continues to be populated, and what applications are possible when users are no longer restricted by data access or processing limitations. Moreover, knowledge of the archive is required to determine the science and applications options that are possible for a given location or extent (i.e., regional to global). The required information on image availability is both geographic and temporal: given cloud cover, shadows, and related causes of view obscurity and past acquisition strategies, are there enough images to make a map for a given time period? (geographic completeness); are there enough images to do change detection or time series analysis? (temporal coverage); are there enough images to undertake time series analysis over a large area? (geographic and temporal). Questions such as these are further complicated by considerations such as the level of processing of images in the archive (e.g., L1T verses L1G), acquisition date, and sensor, with the eventual image yield less than the total number of images present.

The most recent Landsat satellite-Landsat-8 - benefits from the inclusion of modern technology in sensor and satellite components (Irons et al. 2012). Onboard recording capacity and X-band downlink and receiving capacity are sufficiently high that nearly all terrestrial collection opportunities are made. By comparison, Landsats- 1 to -3 had very limited onboard data recording capacity, while Landsats-4 and -5 had no onboard recording capacity and also suffered technical problems with data relay capabilities (Markham et al. 2004). The Landsat-5 TM relay capability failed in 1992. The primary Ku-band link 
failed in July 1988 and the redundant link in July 1992. Following this failure, data transmission became limited to direct, real-time X-band transmission and only Landsat 5 TM data sensed within a U.S. ground station line-of sight were copied to the USGS archive (Chander et al., 2007). These limitations led to a reliance on the network of International Ground Stations (IGS), operated by International Cooperator (IC) nations. These ICs partnered with the Landsat program and paid an annual fee for reception and data distribution rights (Draeger et al. 1997). Although there was never any systematic process implemented to enable the transfer of data acquired by ICs to the USGS Landsat data archive housed at the Earth Resources Observation and Science (EROS) Center in Sioux Falls, South Dakota, the ICs were obligated, through formal Memoranda of Understanding (MOU), to periodically forward image metadata to the USGS. Goward et al. (2006) noted that the metadata transfers were rarely enforced, leading to a general lack of knowledge concerning the extent or quality of the data held by the ICs. The status quo was that while the USGS maintained its Landsat data archive at EROS, ICs were simultaneously building and maintaining their own regional archives, and had the freedom to process and distribute the data according to their own policies and mechanisms (Draeger et al. 1997).

As reported in 2006, it became increasingly apparent that the volume of Landsat data holdings held by ICs far exceeded what was held by the USGS Landsat archive (Goward et al. 2006). As of March 2006, the USGS archive held an estimated 1.9 million images, while it was estimated that ICs held an additional 4 million images. Recognizing the value of these data and wanting to safeguard the considerable investment that had been made in the Landsat Program and realize its full benefit, the USGS-NASA Landsat Science Team recommended in early 2007 that the USGS build upon the information reported by Goward et al. (2006) and initiate the consolidation of the data from the ICs into the USGS Landsat data archive. Only then would there exist a truly global archive processed in a consistent manner that would improve the utility of the data for all users (Loveland and Dwyer 2012). The Landsat Global Archive Consolidation (LGAC) initiative was commenced in early 2008 and continues today. As a result of LGAC and technological improvements in data storage and transmission realized onboard Landsat-8, the current Landsat archive is geographically broader and temporally deeper than at 
any other time. This depth and breadth, combined with free and open access, has fundamentally changed the way Landsat data are being used (Wulder et al. 2012; Kennedy et al. 2014; Roy et al. 2014). Applications using all available images for a given location are increasingly the norm (Zhu and Woodcock, 2014; Brooks et al. 2014) and mapping land resources on global scales is now possible (Gong et al. 2013; Hansen et al. 2013). As suggested by Bolden (2015), the world does indeed rely on Landsat data and, moreover, guided by plans articulated in the 2016 U.S. Presidential budget (Foust, 2015), is poised to do so for decades to come.

In this paper, we describe the current status of the archive and the inception and evolution of the LGAC initiative. For context, we provide a brief synopsis of the Landsat program and document the status of the USGS Landsat data archive holdings as of January 1, 2015. We likewise document current acquisition status and strategies associated with the operation of Landsats-7 and -8 , and look forward to acquisition capacity in the future and avail upon lessons learned to inform proposed operational land imaging activities. Our primary objective is to quantify the current and expected future contributions of LGAC to the USGS Landsat archive and in so doing, make a case for the important role that LGAC has played in both securing the historical legacy of the Landsat program and ensuring the continuity of the Landsat program into the future.

\section{Background and current archive status}

The first of the Landsat series, then known as the Earth Resources Technology Satellite (ERTS), was launched on July 23, 1972. The Earth observation program William Pecora envisioned in the 1960s (Pecora, 1966) has now evolved to the point that data from Landsat are now indispensable for science and natural resource management (Roy et al. 2014). Landsat data are in constant use for agricultural management, yield forecasting and insurance, for land use and cover change, for forestry, water resource management, study of ecosystem services and functioning, for climate science and climate change studies, for studying snow and ice, coastal areas, deserts, geology, soils, urban change and transport among many other applications. The data are used in science programs, they are used by educators in 
schools and universities worldwide, they help decision makers develop, implement, evaluate and refine policies on scales from local to global; they form a basis for international environmental agreements, for legal use, for agribusiness, humanitarian aid and homeland security (Miller et al. 2013).

Landsat is only one of 73 satellite-based global land observing programs operated by 34 different sovereign states (Belward and Skøien 2015), but Landsat occupies a truly unique place in this pantheon, as illustrated by the following:

- Landsat-1 was the first near polar orbiting satellite capable of observing the Earth's landmass at human scales (Townshend and Justice 1988);

- The Landsat Program was the first to employ a global image acquisition strategy;

- Landsat is the longest running uninterrupted Earth observation program, and

○ At 28 years and 10 months of operation, Landsat-5 the longest-lived individual satellite, operating for almost twice as long as any other Earth observing satellite (and there have been more than 200);

- The Landsat archive was the first to offer global imagery at $30 \mathrm{~m}$ resolution without restriction in a free and open manner (Woodcock et al. 2008);

- Landsat is the only program offering a cross-calibrated Earth observation record spanning more than four decades (Markham and Helder 2012);

- Landsat data are more widely used than any other for ecological applications (Cohen and Goward 2004), are the basis for more than twice as many refereed papers dealing with land cover than any other system (Belward and Skøien 2015) and are preeminent for the study of forested environments (Wulder et al. 2012). William Pecora's vision from almost 50 years ago was prescient—Landsat is indeed Earth's resource satellite program.

While the vision of the 1960s may have been on target, mission management has varied substantially over the Program's forty-three year lifespan, shifting from public to commercial responsibility and back again (Loveland and Dwyer 2012). Among many consequences, such as 
fluctuating costs of acquiring Landsat data (Wulder et al. 2008), these changes caused considerable geographic and temporal disparities in the archive (Goward et al. 2006). After initiating a robust acquisition approach during the early 1970s, monitoring the totality of the Earth's land surface became more aspirational than reality; IC ground receiving stations acquired data in line of sight, but there were gaps in the distribution of these stations (and not all maintained assiduous archives, nor did they provide data to the USGS), tracking and data relay satellites did not always work, and on-board recording capacity was severely limited. For example, with the 1999 Landsat-7 launch some ICs switched their reception from Landsat-5 to Landsat-7 but when the Landsat-7 ETM + scan line corrector (SLC) system failed in May 2003 (Markham et al. 2004) several ICs discontinued Landsat-7 acquisitions and changed their operations back to Landsat-5 (Kovalskyy and Roy, 2013).

After 1999 and with the launch of Landsat-7, the program's Long-Term Acquisition Plan (LTAP) improved global coverage (Arvidson et al. 2001). Under the LTAP, every sunlit scene (solar zenith angle less than $85^{\circ}$ in the Southern Hemisphere and less than $75^{\circ}$ in the Northern Hemisphere) overpassed by Landsat-7 covering the conterminous United States (CONUS) and the main U.S. islands was acquired and archived. Alaskan Landsat-7 scenes were acquired under the LTAP in the same way but with cloud avoidance criteria introduced in 2002 (Arvidson et al., 2006). Globally, the LTAP follows a systematic acquisition schedule that refreshes annually the USGS Landsat archive with the goal of at least one sunlit, substantially cloud-free acquisition per season (Arvidson et al., 2001, 2006).

Landsat is a sun synchronous polar orbiting satellite, with an opportunity to collect imagery over a geographic swath of the Earth on each overpass. The Landsat program has used a spatial referencing system to catalogue all images. There have been two versions of the Worldwide Reference System (WRS), Landsats-1 to -3 used WRS-1, and Landsat-4 and all subsequent Landsats have used WRS-2. The WRS partitions Landsat images into approximate 185 x $185 \mathrm{~km}$ squares, known as scenes. The actual data realizations for each scene are referred to as images. 


\subsection{USGS Landsat archive status (January 1, 2015)}

The USGS Landsat data archive currently contains more than 5.5 million images (Table 1; Figure 1). The bulk of these images (70\%) were acquired from the Landsat-5 Thematic Mapper (TM) and Landsat-7 Enhanced Thematic Mapper Plus (ETM+) sensors. Relative to TM data, the acquisition of ETM+ was historically more spatially and temporally systematic as a result of the LTAP (Arvidson et al. 2001, 2006) and the ability of Landsat-7 to store global data onboard for later downlink. For Landsat-8's Operational Land Imager (OLI) and Thermal Infrared Sensor (TIRS) there is reduced emphasis on LTAP because of improved high capacity onboard recording and satellite to ground transmission capabilities such that nearly all possible terrestrial observations can be acquired and transmitted (Roy et al. 2014). The combined acquisition capacity of the Landsats- 7 and -8 is currently approximately 1200 scenes per day. This has led to a rapidly accelerated rate at which imagery is being added to the Landsat archive. As indicated in Table 1, OLI has acquired a considerable number of images since its operational phase commenced in May 2013, with more than 385,000 images acquired. OLI is adding data to the archive at an annual rate that is 3.5 times that of TM, and 1.8 times that of ETM+, and has already provided almost $10 \%$ of the Landsat $30 \mathrm{~m}$ resolution data record.

Also of note is the average data volume per image for OLI, which at $1813 \mathrm{MB}$ is 57 times larger than Multispectral Scanner (MSS) data, and 4 times larger than ETM+. As a result, after only two years in operation, the total volume of OLI data in the archive is already 1.3 times greater than the 32 years of TM data from Landsats- 4 and -5 that the archive currently contains. Figure 1 shows that the geographical distribution of images in the USGS archive is globally complete, but not globally consistent. Although some images may be cloudy all continents and islands have been imaged more than once - the LGAC has produced a truly global archive. However, North America, Australia, and Eastern China have the greatest temporal depth, while north-central Africa and northern Russia have the sparsest coverage. The sparse coverage in north-central Africa and Russia are largely due to the lack of IC station coverage, resulting in coverage limited to U.S. acquisitions and those made possible by temporary, regionally focused, collection campaigns using a temporary station. Again, it is noted that the number of images in the 
archive as of January 1, 2015 is the product of both USGS collections and the additions, to that date, from the LGAC initiative.

Table 1. Status of the USGS archive as of January 1, 2015.

\begin{tabular}{lrrrrr}
\hline Sensor & $\begin{array}{r}\text { Number of } \\
\text { images }\end{array}$ & $\begin{array}{r}\text { Total } \\
\text { data volume } \\
\text { in archive } \\
\text { (TB) }\end{array}$ & $\begin{array}{r}\text { Average data } \\
\text { volume per } \\
\text { image (MB) }\end{array}$ & $\begin{array}{r}\text { Years } \\
\text { in operation }\end{array}$ & $\begin{array}{r}\text { Annual image } \\
\text { acquisition rate (Total } \\
\text { scenes/year) }\end{array}$ \\
\hline MSS & $1,299,626$ & 79 & 32 & 42.4 & 30,652 \\
TM & $1,988,982$ & 997 & 263 & 32.4 & 61,388 \\
ETM+ & $1,858,501$ & 1,726 & 487 & 15.6 & 119,135 \\
OLI & 385,345 & 1,332 & 1,813 & 1.8 & 214,081 \\
\hline Total & $\mathbf{5 , 5 3 2 , 4 5 4}$ & $\mathbf{4 , 1 3 4}$ & & &
\end{tabular}

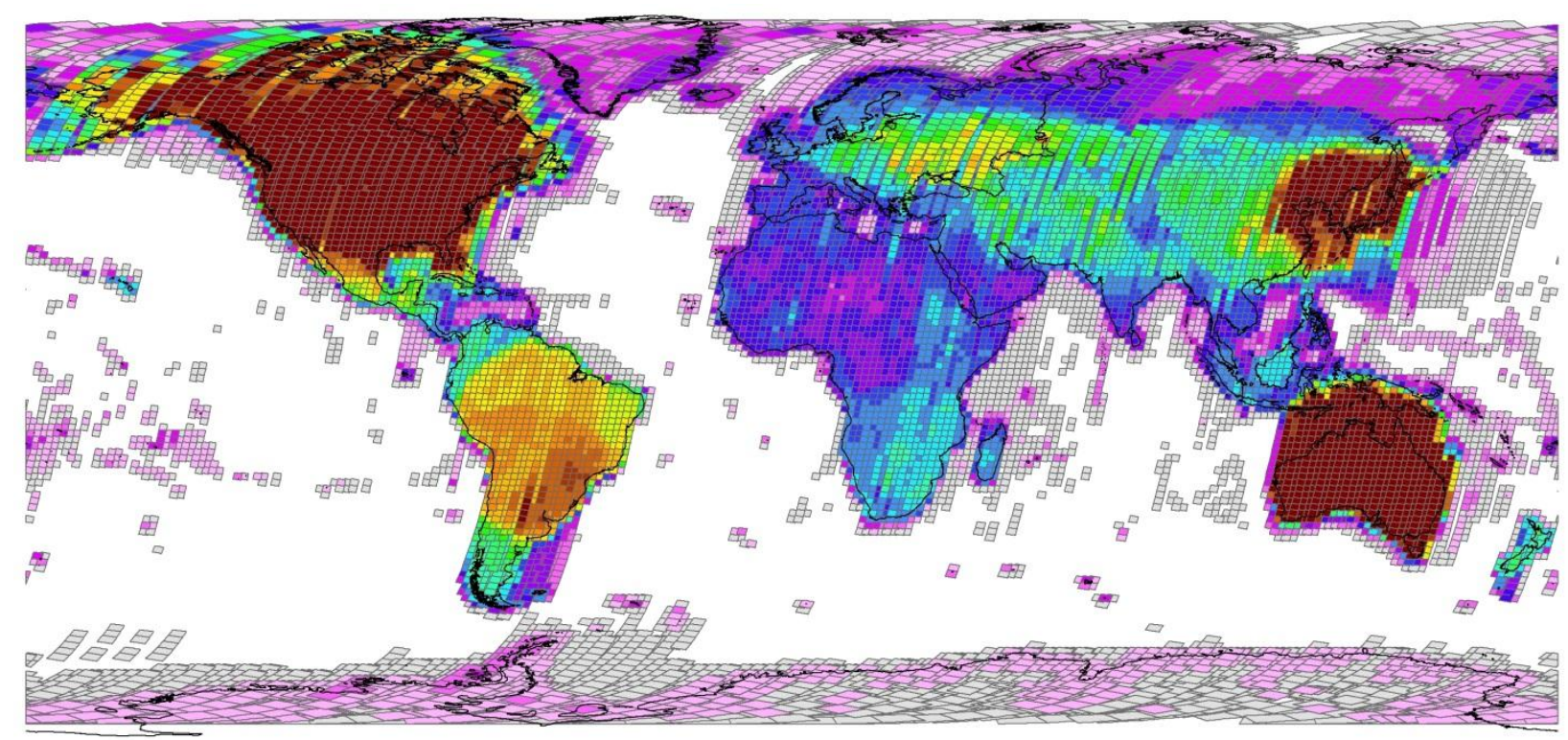

\section{Number of images}

\begin{tabular}{|c|c|c|c|c|}
\hline $1-50$ & $201-250$ & $401-450$ & $601-650$ & $801-850$ \\
\hline $51-100$ & $251-300$ & $451-500$ & $651-700$ & $851-900$ \\
\hline $101-150$ & $301-350$ & $501-550$ & $701-750$ & $901-950$ \\
\hline $151-200$ & $351-400$ & $551-600$ & $751-800$ & $>950$ \\
\hline
\end{tabular}

Figure 1. USGS Landsat archive holdings as of January 1, 2015. 


\section{Landsat Global Archive Consolidation (LGAC)}

\subsection{Conception of the LGAC initiative}

A significant artifact of the complex technical and programmatic history of Landsat is that much of the data collected from Landsats-1 through -5 did not reside in the Landsat Archive at the USGS EROS Center. IC ground stations have collected Landsat images since the launch of Landsat-1 in July 1972. Since that time, more than 50 ground stations have been configured to receive Landsat data, although the number of active ground stations has varied over the course of the program's history (Goward et al. 2006). Following an extensive investigation of scene-level metadata, several ground stations operated by various nation states (or regional groupings of nation states as in the case of the European Space Agency [ESA]) were identified that have significant, unique, historical Landsat data not duplicated in the USGS Landsat archive (Figure 2, Table 2).

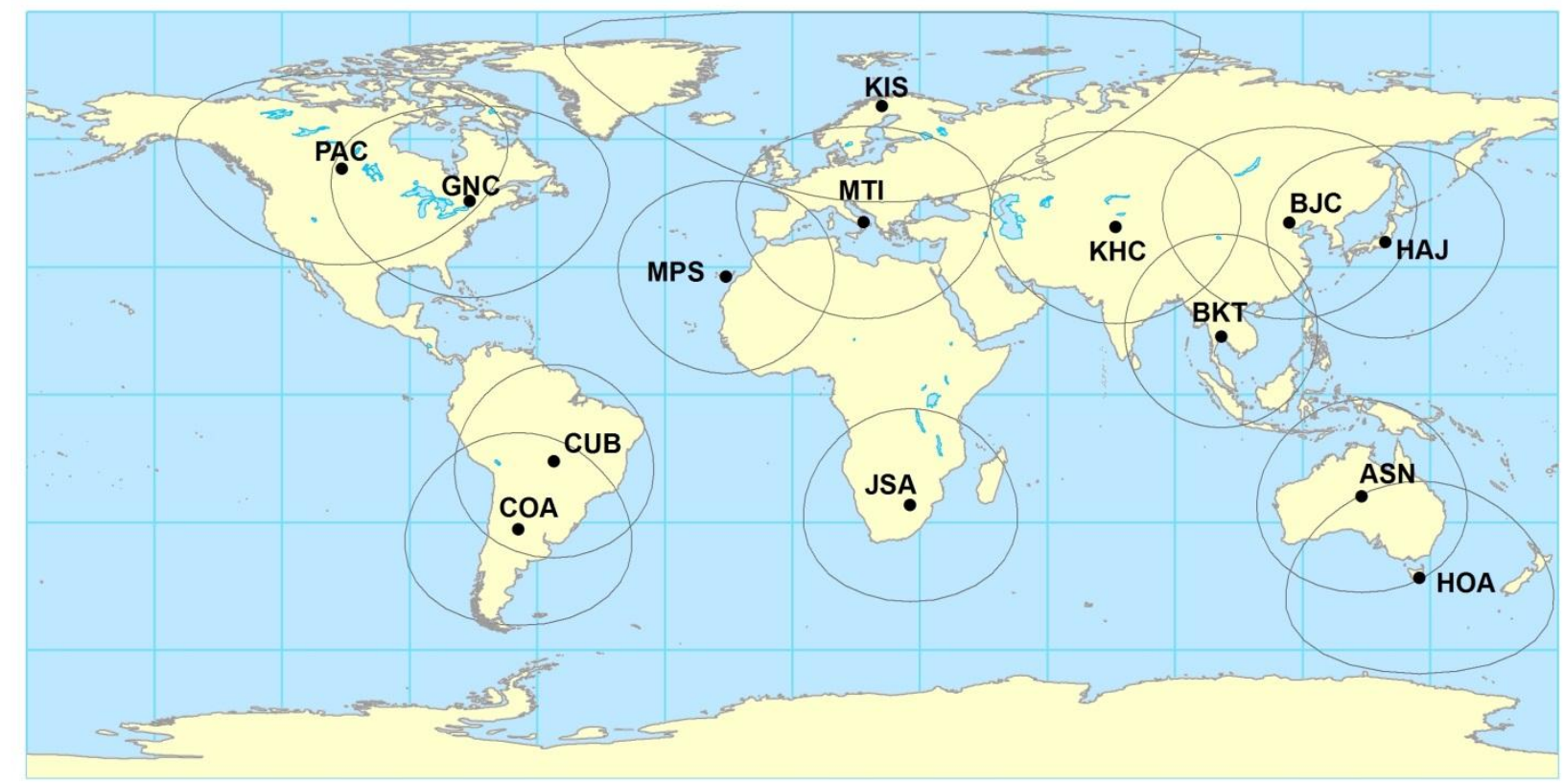

Figure 2. Key International Cooperators (ICs) and International Ground Stations (IGS) with notable holdings of Landsat images unique to the archive (After USGS: http://landsat.usgs.gov//about_ground_stations.php). See Table 2 for the key to station IDs. 
Table 2. Listing of International Cooperators (IC) and International Ground Stations (IGS) (After USGS: http://landsat.usgs.gov//Historical_IGS.php).

\begin{tabular}{|c|c|c|c|c|c|c|c|}
\hline Country & Org. & $\begin{array}{l}\text { Ground } \\
\text { Station } \\
\text { Location }\end{array}$ & $\begin{array}{l}\text { Ground } \\
\text { Station } \\
\text { ID }\end{array}$ & Landsat 1-5 MSS & Landsat 4-5 TM & Landsat 7 ETM+ & $\begin{array}{l}\text { Landsat } 8 \text { OLI / } \\
\text { TIRS }\end{array}$ \\
\hline $\begin{array}{l}\text { Argentin } \\
\text { a }\end{array}$ & CONAE & $\begin{array}{l}\text { Córdoba, } \\
\text { Argentina }\end{array}$ & $\mathrm{COA}$ & & Jan 1997 - Nov 2011 & Jul 1999 - Current & Nov 2013 - Current \\
\hline \multirow[t]{2}{*}{ Australia } & GA & $\begin{array}{l}\text { Alice Springs, } \\
\text { Australia }\end{array}$ & ASA & $\begin{array}{l}\text { L2 MSS: Sep } 1979 \text { - Mar } 1982 \\
\text { L3 MSS: Nov } 1979 \text { - Nov } 1982 \\
\text { L4 MSS: Jun } 1982 \text { - Jul } 1987 \\
\text { L5 MSS: Apr } 1984 \text { - Dec } 1997\end{array}$ & $\begin{array}{l}\text { Aug } 1986 \text { - Jan 2000; } \\
\text { Jul } 2003 \text { - Nov } 2011\end{array}$ & May 1999 - Current & Mar 2013 - Current \\
\hline & & Hobart, Australia & HOA & & Nov 2003 - Nov 2011 & Jul 1999 - Jan 2012 & \\
\hline Brazil & INPE & Cuíaba, Brazil & CUB & $\begin{array}{l}\text { L1 MSS: May } 1973 \text { - Dec } 1976 \\
\text { L2 MSS: Jul } 1975 \text { - Feb } 1982 \\
\text { L3 MSS: Apr } 1978 \text { - Aug } 1982 \\
\text { L4 MSS: Sep } 1982 \text { - Dec } 1984\end{array}$ & Apr 1984 - Nov 2011 & $\begin{array}{l}\text { Jul } 1999 \text { - Jun 2003; } \\
\text { Feb } 2012 \text { - Current }\end{array}$ & \\
\hline \multirow[t]{2}{*}{ Canada } & CCMEO & $\begin{array}{l}\text { Gatineau, } \\
\text { Canada }\end{array}$ & GNC & $\begin{array}{l}\text { L5 MSS: Jul } 1992 \text { - Aug 1992; } \\
\text { Jun } 1996 \text { - May } 1999\end{array}$ & $\begin{array}{l}\text { Aug } 1982 \text { - Oct 1999; } \\
\text { Apr } 2003 \text { - Nov } 2011\end{array}$ & Jul 1999 - Apr 2006 & \\
\hline & & $\begin{array}{l}\text { Prince Albert, } \\
\text { Canada }\end{array}$ & PAC & $\begin{array}{l}\text { L1 MSS: Aug } 1972 \text { - Oct } 1977 \\
\text { L2 MSS: Apr } 1975 \text { - Feb } 1982 \\
\text { L3 MSS: May } 1978 \text { - Feb } 1983 \\
\text { L5 MSS: Jul } 1990 \text { - Aug } 1999 ; \\
\text { Apr } 2012 \text { - Oct } 2012\end{array}$ & $\begin{array}{l}\text { Oct } 1982 \text { - Oct 1999; } \\
\text { Apr } 2003 \text { - Nov } 2011\end{array}$ & Jul 1999 - Apr 2006 & Jul 2013 - Current \\
\hline \multirow[t]{2}{*}{ China } & RADI & Beijing, China & $\mathrm{BJC}$ & & Apr 1986 - Nov 2011 & Jul 1999 - Sep 2004 & Jul 2013 - Current \\
\hline & & KaShi, China & $\mathrm{KHC}$ & & Apr 2008 - Nov 2011 & & Nov 2014 - Current \\
\hline Italy & ESA & Matera, Italy & MTI & & Jun 2001 - Nov 2011 & Jun 2001 - Dec 2003 & Nov 2013 - Current \\
\hline Spain & $\begin{array}{l}\text { ESA- } \\
\text { INTA }\end{array}$ & $\begin{array}{l}\text { Maspalomas, } \\
\text { Spain }\end{array}$ & MPS & & $\begin{array}{l}\text { Oct } 2006 \text { - Oct 2007; } \\
\text { Jun } 2009 \text { - Nov } 2011\end{array}$ & $\begin{array}{l}\text { Dec } 1999-\text { Dec } \\
2003\end{array}$ & \\
\hline
\end{tabular}


Table 3. (continued)

\begin{tabular}{|c|c|c|c|c|c|c|c|}
\hline Country & Org. & $\begin{array}{l}\text { Ground } \\
\text { Station } \\
\text { Location }\end{array}$ & $\begin{array}{l}\text { Ground } \\
\text { Station } \\
\text { ID }\end{array}$ & Landsat 1-5 MSS & Landsat 4-5 TM & Landsat 7 ETM+ & $\begin{array}{l}\text { Landsat } 8 \text { OLI / } \\
\text { TIRS }\end{array}$ \\
\hline Sweden & $\begin{array}{l}\text { ESA / } \\
\text { SSC }\end{array}$ & Kiruna, Sweden & KIS & $\begin{array}{l}\text { L2 MSS: May } 1978 \text { - Mar } 1982 \\
\text { L3 MSS: Mar } 1979 \text { - Oct } 1982 \\
\text { L4 MSS: Aug } 1982 \text { - Aug } 1983 \\
\text { L5 MSS: May } 1984 \text { - Oct } 1993\end{array}$ & $\begin{array}{l}\text { May } 1984 \text { - Aug 1999; } \\
\text { Apr } 2004 \text { - Oct 2006; } \\
\text { Jun } 2009 \text { - Nov } 2011\end{array}$ & Jul 1999 - Jun 2003 & Apr 2014 - Current \\
\hline \multirow[t]{2}{*}{ Japan } & $\begin{array}{l}\text { JAXA/RE } \\
\text { STEC }\end{array}$ & Hatoyama, Japan & HAJ & $\begin{array}{l}\text { L2 MSS: Feb } 1979 \text { - Feb } 1982 \\
\text { L3 MSS: Jan } 1979 \text { - Mar } 1983 \\
\text { L4 MSS: Oct } 1982 \text { - Oct } 1987 \\
\text { L5 MSS: Apr } 1984 \text { - Jan } 1999\end{array}$ & Apr 1984 - Sep 2010 & $\begin{array}{l}\text { May } 2000 \text { - May } \\
2003\end{array}$ & May 2013 - Current \\
\hline & $\begin{array}{l}\mathrm{JAXA} / \mathrm{HI} \\
\text { T/HEEIC }\end{array}$ & Hiroshima, Japan & HIJ & & & $\begin{array}{l}\text { Mar } 2000 \text { - April } \\
2009\end{array}$ & \\
\hline $\begin{array}{l}\text { South } \\
\text { Africa }\end{array}$ & AIST & $\begin{array}{l}\text { Hartebeesthoek, } \\
\text { South Africa }\end{array}$ & JSA & $\begin{array}{l}\text { L2 MSS: Dec } 1981 \text { - Feb } 1982 \\
\text { L4 MSS: Feb } 1984 \text { - Jan } 1987 \\
\text { L5 MSS: Sep } 1985 \text { - May } \\
\text { 1990; } \\
\text { Jun } 1993 \text { - Oct } 1993\end{array}$ & $\begin{array}{l}\text { Jan } 1989 \text { - Aug 2001; } \\
\text { Aug } 2003 \text { - Jun } 2011\end{array}$ & $\begin{array}{l}\text { Aug } 2001 \text { - Mar } \\
\text { 2003; } \\
\text { Nov } 2012 \text { - Current }\end{array}$ & Jun 2013 - Current \\
\hline Thailand & GISTDA & $\begin{array}{l}\text { Bangkok, } \\
\text { Thailand }\end{array}$ & BKT & $\begin{array}{l}\text { L2 MSS: Nov } 1981 \text { - Dec } 1982 \\
\text { L3 MSS: Sep } 1980 \text { - Aug } 1983 \\
\text { L4 MSS: Jan } 1983 \text { - Oct } 1987 \\
\text { L5 MSS: Apr } 1984 \text { - Nov } 1988\end{array}$ & $\begin{array}{l}\text { Dec } 1987 \text { - Sep 2001; } \\
\text { Sep } 2004 \text { - Nov } 2011\end{array}$ & Feb 2001 - Jun 2004 & Aug 2014 - Current \\
\hline
\end{tabular}


Due to early programmatic policies ICs with direct downlinks of data from the Landsat satellites were not required to share their acquisitions with the U.S. archive (at the time, the USGS was managing the archive under agreements made within the US government (e.g., with NOAA)). Following the "Land Remote Sensing Policy Act of 1992", as described in Wulder et al. (2008), the USGS took over full responsibility for the archive in 1992. Moreover, and as indicated earlier, although there were formal MOUs governing the provision of metadata from the ICs to the U.S. archive, these MOUs were not enforced, leaving the USGS with little information on the quantity, or quality, of Landsat data that the ICs were acquiring; and as stated in the introduction the technical limitations related to onboard storage and data relay capabilities meant that the ICs held a significant proportion of the imagery acquired during the first 30 years of the Landsat program. The National Satellite Land Remote Sensing Data Archive (NSLRSDA) initiated a detailed investigation into the Landsat holdings of both the USGS and the ICs. The initial results, published in Goward et al. (2006), contributed to a growing understanding that there were more Landsat data held outside of, rather than within, the USGS archive. Goward et al. (2006) found that approximately 4.2 million images were held by ICs (with one-third of those held by ESA) compared with USGS holdings at that time of fewer than 1.9 million images.

The full magnitude of Landsat data held outside of the USGS archive became increasingly apparent during efforts to compile global image libraries, such as for GEOCover and the Global Land Survey (e.g., Gutman et al. 2008, 2013). Moreover, the need for consistent global datasets for specific time periods brought increased community awareness to the invaluable image data maintained by the IC community. At the time, users interested in obtaining non-USGS Landsat holdings were required to contact and purchase the data directly from the IC that archived it. Differences in data formats and level of processing varied, increasing the efforts required to use the historical Landsat data held by ICs. Moreover, data from inactive IGSs were not accessible, and storage and security of those historical Landsat scenes was tenuous.

In early 2007, the first meeting of the newly convened USGS/NASA Landsat Science Team (LST) discussed the need to consolidate all holdings of Landsat in a common archive (Loveland et al. 2007a). At 
the subsequent meeting later that year, the following quote from the meeting summary illustrates the cautious initial discussions (Loveland et al., 2007b):

"While the international ground stations hold significant amounts of historical Landsat data, the longterm viability of those data could, in some cases, be in jeopardy. In addition, the international holdings represent an invaluable collection needed by the science and applications user community. What is the possibility for expanding the National Satellite Land Remote Sensing Data Archive (NSLRSDA) with Landsat data from international cooperator holdings?" "

It is important to remember that this discussion preceded the late-2008 initiation of the free and open access Landsat data policy by almost two years, and it was unimaginable at that time that people would be doing global analyses with Landsat data (e.g., Hansen et al. 2013, Gong et al. 2013) or that analyses would involve such intensive mining of the archive (e.g., Roy et al. 2010; Zhu and Woodcock 2014; Hermosilla et al. 2015). The focus was squarely on the need to preserve the data for posterity, as there were reports that some of the IC Landsat data holdings were on degrading media. At the following LST meeting six months later, a goal was established that "by the launch of the LDCM in mid-2011, all the existing imagery collected by prior Landsats be consolidated in the U.S. archive and made equally accessible as LDCM imagery" (Loveland et al., 2007b).

The first report back to the LST provided an initial attempt to determine how many unique images (i.e., images not already in the USGS archive) were held by each of the ICs (Loveland et al., 2008). At this stage of the process, the USGS sought help from the Science Team members to identify contacts for some of the ICs, as some ICs were no longer actively receiving Landsat images or their relationships with the USGS had lapsed. Thus, not only were the status of the IC holdings not fully known, but in some cases, the IC status or contact information was also unknown. Following notable efforts by both scientific and professional staff (from across the IC community and the USGS), the initial metadata analysis evolved into a full inventory of images held by the majority of ICs. As the LGAC initiative formalized, the goals and key activities identified for a global consolidated archive were identified and articulated: 
- Determination of the willingness of the ICs to participate in this effort;

- Documentation of the location, extent, and condition of the historical Landsat archives around the world;

- Generation of a list of the instrument (Return Beam Vidicon, MSS, TM, ETM+), data format, and media type at each location;

- Assessment of the equipment, software, logistics, and level of effort necessary to acquire, ingest, process, and archive the data; and,

- Development of a cost estimate and schedule for establishing a global consolidated archive.

\subsection{LGAC implementation}

There have been formidable challenges associated with implementing LGAC. One of the early concerns was that the ICs might not be willing to simply share their holdings of Landsat images with the USGS, as they had initially paid a fee for the opportunity to receive and distribute Landsat data. Additionally, most IC business models depended upon data sales as an income source, so transferring Landsat data to the USGS for incorporation into a free, global archive housed at EROS could undermine their regional solesource position. Although the 2008 "free and open" data policy was expected to be a significant disincentive for IC participation in LGAC, the advantage to the ICs was having the data transferred from storage on tape and processed into standard L1T products, a process that many ICs could not undertake on their own. By processing the data to a standard product (L1T), it improved the utility for everyone, even users in the countries providing images. An additional USGS programmatic concern was the challenge of allocating resources to a multi-year initiative during a period of expanding Landsat product generation and Landsat data distribution, as well as building the LDCM ground system. What began as a challenging programmatic process quickly evolved into a full-fledged technical challenge. As more ICs agreed to contribute to the initiative, the USGS began to shift its focus and resources to support LGAC implementation. 
Interaction with the ICs was conducted through the annual meetings of the Landsat Ground Station Operators Working Group (LGSOWG) and the Landsat Technical Working Group (LTWG), both comprised of representatives from each IC. Early leadership in LGAC came from Australia, Brazil, and Canada (Wulder et al. 2012), and gradually all of the active and inactive ICs committed to sharing images with the USGS EROS Center under the LGAC banner (contributing ICs are shown in Figure 2). Even inactive stations in Ecuador, India, Pakistan, and Saudi Arabia have made institutional commitments to the LGAC process and have transferred their Landsat data holdings.

The ultimate aim of LGAC is to ingest and apply standard Level 1 Product Generation System (LPGS) processing to generate an L1T analysis-ready product (that is, implementation of a suite of processing steps previously required of data end-users, including precision georegistration, radiometric calibration, and orthorectification using digital topography (for additional detail, see Wulder et al. (2012) and Hansen and Loveland (2012)). Initially, LGAC emphasis was on adding Landsat TM and ETM+ holdings, followed by the earlier MSS record. Consolidation of the TM record is especially important due to the aforementioned 1992 loss of the Landsat 5 data relay capabilities. The MSS transfer has proven to be particularly challenging due to unique and partially processed data formats that make scene reconstitution and geometric processing more difficult, exacerbated by the fact that the MSS data from many of the ICs was stored on what is now uncommon tape-based storage media, much of which is deteriorated (due to the age and the nature of the storage media as well as the storage practices and facilities utilized).

There have been notable technical challenges associated with antiquated media, degrading media, and unfamiliar data formats. Some ICs have transferred data to the USGS EROS electronically, while others have packaged and shipped crates containing old media. The latter has required novel approaches for reconstructing outmoded recording devices and recovering data on deteriorating media. In some cases, ICs provided old electronic devices and spare components so that the tape drives needed to recover the data could be restored. Despite these challenges, the recovery rate has been impressive as a result of the skill and ingenuity of the technical experts at EROS. Approximately 3.2 million images have been added 
to the USGS archive so far, and an additional 2.3 million images remain to be added. The remaining images include older media and the MSS record, so the process of transferring these data into the USGS archive will likely take longer than the initial transfer of TM and ETM+ data. As illustrated by the European station holdings, the lack of appropriate metadata can also slow ingest. For example, Payload Correction Data (PCD) files containing the definitive attitude and ephemeris parameters needed for precise georegistration are missing for approximately 500,000 Landsat 5 TM scenes from Kiruna station. Analysis is underway to determine how to process these scenes.

\subsection{LGAC current status and future contributions}

To fully appreciate the success of the LGAC to date, it is necessary to understand the state of the USGS archive pre-LGAC. Figure 1 illustrates the current status of the archive as of January 1, 2015 including all data holdings added as a result of the LGAC to that date. In contrast, Figure 3 shows what the status of the archive would have been as of January 1, 2015 without the data holdings added through the LGAC initiative. Note the markedly different coverage for most areas outside of the CONUS and Alaska, particularly over, Canada, Europe, Australia, and South America. 


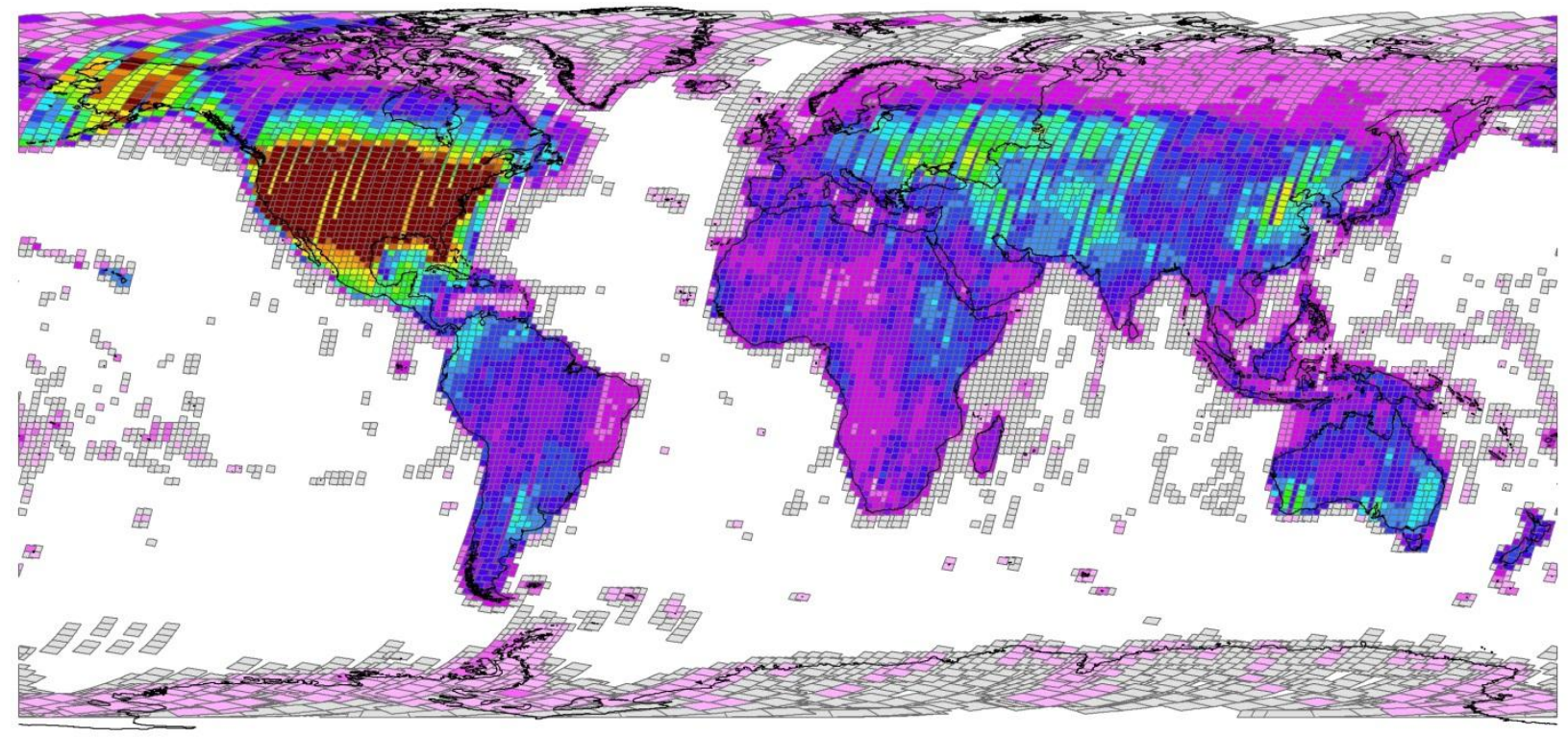

\section{Number of images}

\begin{tabular}{|c|c|c|c|c|}
\hline $1-50$ & $201-250$ & $401-450$ & $601-650$ & $801-850$ \\
\hline $51-100$ & $251-300$ & $451-500$ & $651-700$ & $851-900$ \\
\hline $101-150$ & $301-350$ & $501-550$ & $701-750$ & $901-950$ \\
\hline $151-200$ & $351-400$ & $551-600$ & $751-800$ & $>950$ \\
\hline
\end{tabular}

Figure 3. What the status of the USGS archive holdings would have been as of January 1, 2015 without LGAC.

As indicated in Figure 3 and Table 3, the total contribution of LGAC to-date has been significant, with the location and amount of the actual additions noted in Figure 4. In the absence of efforts to consolidate data holdings from the ICs, the Landsat archive would have only contained 2.4 million images as of January 1, 2015, indicating that LGAC more than doubled the number of images in the archive (Table 3). Indeed, as illustrated in Figure 1, many of the spatial gaps in the USGS archive holdings that were originally identified in Plate 4 of Goward et al. (2006) (e.g., in Canada, Europe, China, South America) have been, or will be (Figure 5) filled, through the efforts of the LGAC initiative. 
Table 4. Scenarios of archive status as of January 1, 2015 indicating the current and future contributions of LGAC to the total USGS Landsat data holdings.

\begin{tabular}{lrrrr}
\hline Sensor & Without LGAC & $\begin{array}{r}\text { With current LGAC } \\
\text { holdings } \\
\text { (corresponds to } \\
\text { Table 1) }\end{array}$ & $\begin{array}{r}\text { With all potential } \\
\text { LGA holdings that the } \\
\text { USGS has currently } \\
\text { identified }\end{array}$ & $\begin{array}{r}\text { Total LGAC } \\
\text { contribution }\end{array}$ \\
\hline MSS & 498,809 & $1,299,626$ & $1,957,232$ & $1,458,423$ \\
TM & 263,916 & $1,988,982$ & $3,414,118$ & $3,150,202$ \\
ETM+ & $1,204,759$ & $1,858,501$ & $2,085,743$ & 880,984 \\
OLI & 385,345 & 385,345 & 385,345 & NA \\
\hline Total & $\mathbf{2 , 3 5 2 , 8 2 9}$ & $\mathbf{5 , 5 3 2 , 4 5 4}$ & $\mathbf{7 , 8 4 2 , 4 3 8}$ & $\mathbf{5 , 4 8 9 , 6 0 9}$
\end{tabular}

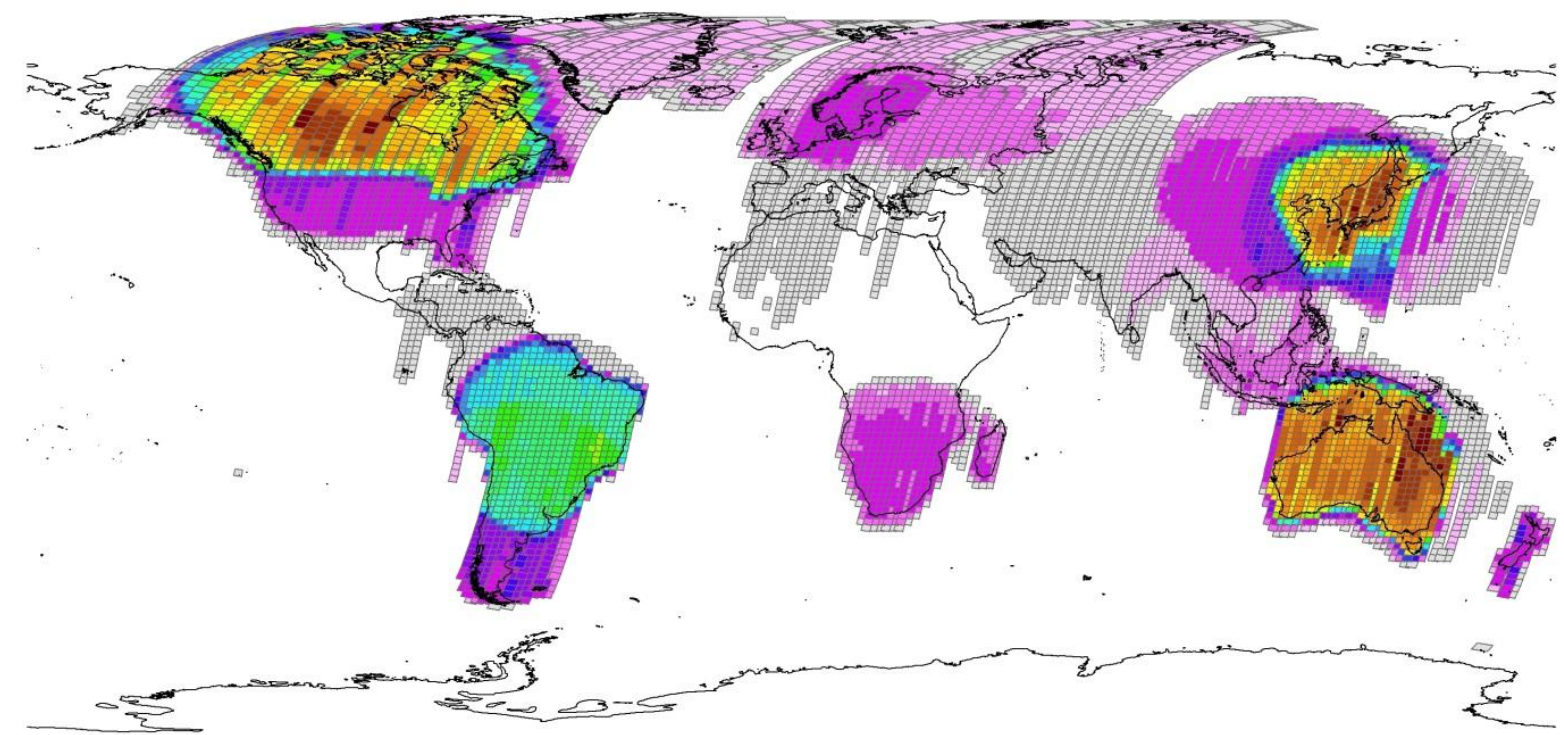

Number of images

\begin{tabular}{|c|c|c|c|c|}
\hline $1-50$ & $201-250$ & $401-450$ & $601-650$ & $801-850$ \\
\hline $51-100$ & $251-300$ & $451-500$ & $651-700$ & $851-900$ \\
\hline $101-150$ & $301-350$ & $501-550$ & $701-750$ & $901-95$ \\
\hline $151-200$ & $351-400$ & $551-600$ & $751-800$ & $>950$ \\
\hline
\end{tabular}

Figure 4. Location and number of images that have been added to the USGS archive holdings via the LGAC as of January 1, 2015. 


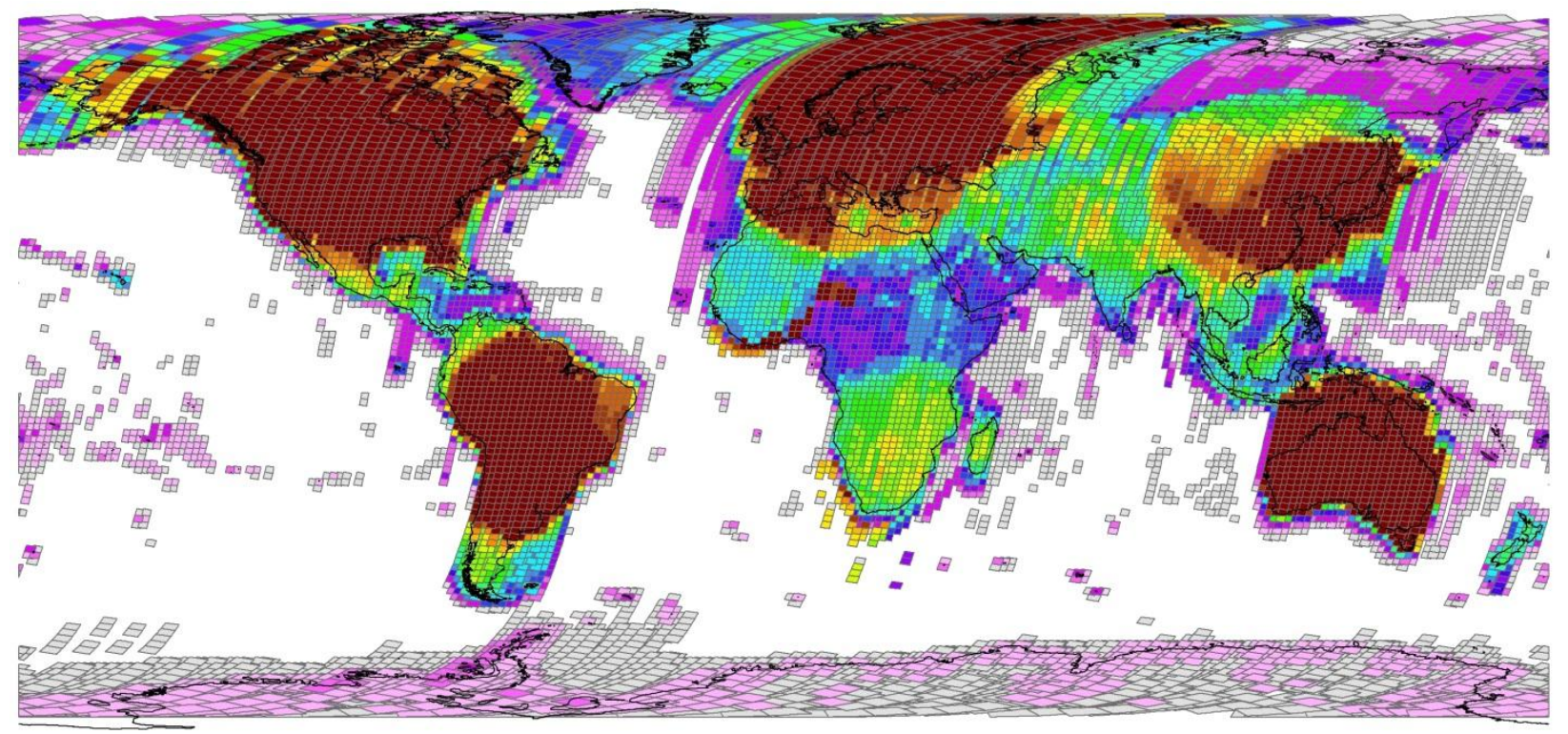

\section{Number of images}

\begin{tabular}{|c|c|c|c|c|}
\hline $1-50$ & $201-250$ & $401-450$ & $601-650$ & $801-850$ \\
\hline $51-100$ & $251-300$ & $451-500$ & $651-700$ & $851-900$ \\
\hline $101-150$ & $301-350$ & $501-550$ & $701-750$ & $901-950$ \\
\hline $151-200$ & $351-400$ & $551-600$ & $751-800$ & $>950$ \\
\hline
\end{tabular}

Figure 5. Potential future state of the archive if all anticipated LGAC holdings (shown in Figure 6) are incorporated.

The LGAC is ongoing, and the total contributions of LGAC to the USGS archive have yet to be fully realized. Figure 5 provides an indication of what the archive will look like once the images not ingested prior to January 1, 2015 are included. Figure 6 shows the location and number of the IC holdings identified to date through the LGAC initiative that remain to be incorporated into the USGS archive. As indicated in Table 3 and based on our current knowledge, the LGAC is poised to contribute an estimated 2.3 million additional images to the USGS archive, to provide a total of 5.5 million consolidated LGAC images. As evident in Figure 6, Europe has a large number of images that remain to be ingested. West Africa, China, South Africa, South America, and Greenland also stand to benefit from continued LGAC activity. For context, Landsat-5, which operated for a remarkable 29 years, acquired approximately 2.5 million images over its lifespan (http://www.nasa.gov/mission_pages/landsat/news/landsat5guinness.html\#.VblgV_lVhBc). The magnitude of the LGAC contribution to the USGS archive is therefore equivalent to that of two Landsat-5 missions. As of January 1, 2015, 57\% of the images in the 
archive are there as a result of the LGAC initiative. It is anticipated that additional IC holdings remain to discovered, with some ICs having informally reported additional images located and intended for inclusion in LGAC, noting that the bulk of available data have been identified by the USGS. The overall number of eventual LGAC images, based upon the current metadata, is more than 5.5 million. In terms of project status, based upon the total number of images available and those remaining to be added, the LGAC effort can be considered just past the halfway point. As indicated earlier, the data that remain to be consolidated into the archive are primarily MSS data and these data pose some particular challenges in terms of media and processing.

LGAC has also enriched the temporal dimension of the archive, adding increased image depth for areas such as Canada, Australia, China, Europe, and southern Africa (Figure 7). Prior to LGAC, denser temporal coverage of Landsat data in the 1970s and 1980s was limited to North America. Most notably, LGAC has increased the temporal depth in the 1970s for South America, and in the 1980s for Europe, northern and southern Africa, eastern China, Southeast Asia, and Australia. The greatest gains in terms of imagery consolidated by LGAC have been realized for the 1990s and 2000s, with those two epochs representing $76 \%$ of all LGAC holdings to date. Indeed, the spatial and temporal coverage for Europe in these two epochs has been markedly improved as a result of LGAC (Figure 7). LGAC gains in terms of temporal depth for the MSS era (1970s) have been modest by comparison; however the aforementioned enhanced coverage for South America during this era as a result of LGAC is noteworthy. 


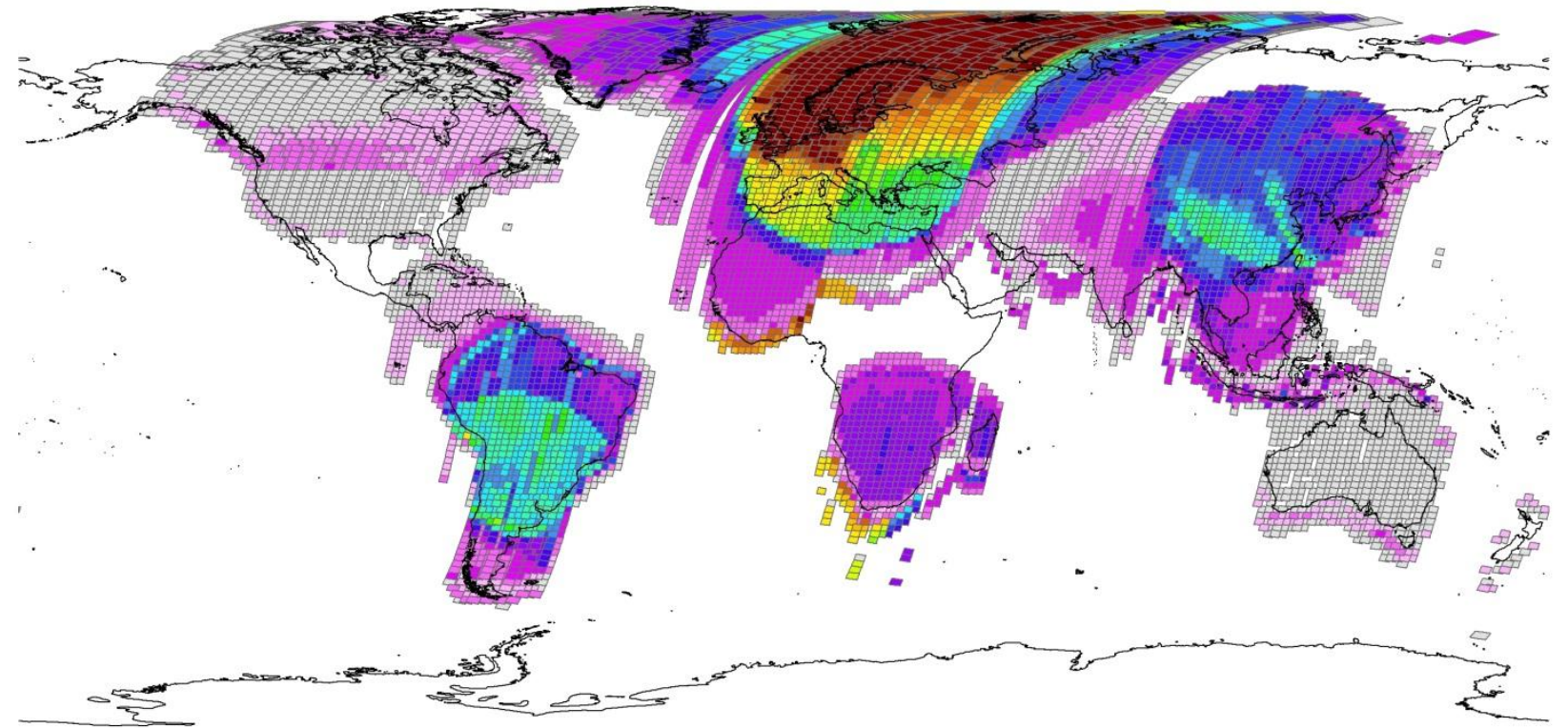

\section{Number of images}

\begin{tabular}{|c|c|c|c|c|}
\hline $1-50$ & $201-250$ & $401-450$ & $601-650$ & $801-850$ \\
\hline $51-100$ & $251-300$ & $451-500$ & $651-700$ & $851-900$ \\
\hline $101-150$ & $301-350$ & $501-550$ & $701-750$ & $901-950$ \\
\hline $151-200$ & $351-400$ & $551-600$ & $751-800$ & $>950$ \\
\hline
\end{tabular}

Figure 6. Location and number of images identified through LGAC that remain to be added to the archive. 


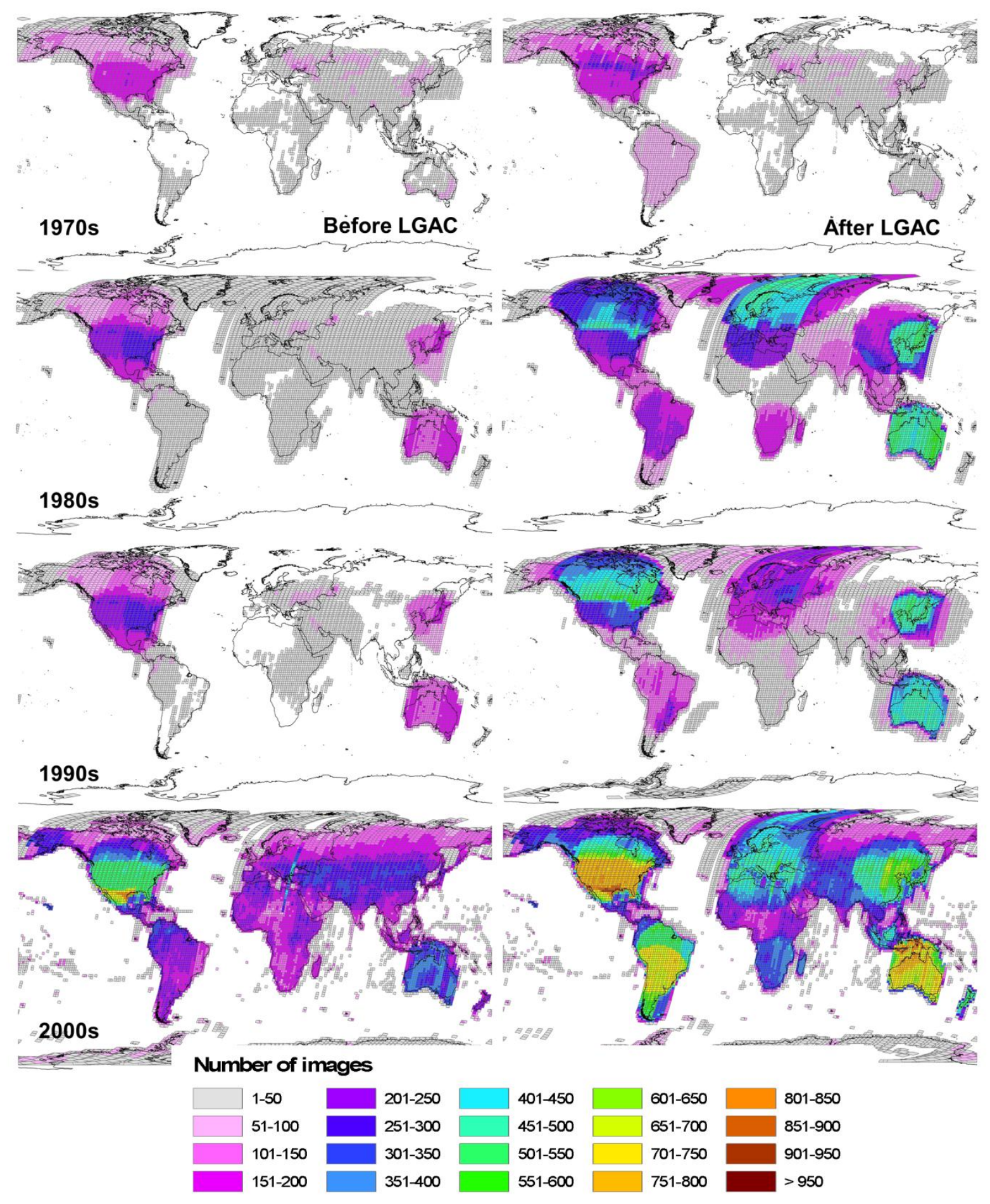

Figure 7. Temporal distribution of USGS Landsat archive holdings before (left) and after (right) LGAC, by 10-year epochs. Note that the 2000 epoch includes images acquired from 2000 to 2014. 


\section{Current Landsat acquisition status and strategies}

The Landsat archive is dynamic. New collections from Landsat-7 and -8 continue to be added to the archive concurrent with those from the LGAC initiative. As a result, knowledge of the current acquisition status and strategies for Landsats-7 and -8 further inform on archive status and potential. With the launch of Landsat-8 significant changes were made to the Long-Term Acquisition Plan (LTAP) for both Landsat7 and -8 , while retaining the core Landsat mission of acquiring as many day-lit descending land images as feasible.

\subsection{Landsat-7 LTAP}

In 2013, the USGS initiated a study of the Landsat-7 LTAP with a goal of increasing Landsat-7 acquisitions focused on continental land masses and reducing the number of ETM+ power cycles and the percent of duty cycles. Landsat-7 has always acquired isolated islands at a lower priority and only imaged at night for emergency response due to duty cycle costs. As an approximate rule of thumb the acquisition of an image for an isolated scene had a cost of six scene-collection opportunities elsewhere. As a consequence of the study, a continental acquisition strategy was implemented in early 2014 to refine the LTAP. Previously, in the summer of 2011, the daily limits had been raised to 400 scenes. In April 2014, after a few months of continental land scheduling, the Landsat-7 daily limits were removed and only system constraints limited acquisition. These actions allowed the number of images per day to increase from 314 in 2010 to 380 in 2012, to 470 at present. The system constraints limiting acquisitions include the amount of onboard memory and the number and distribution of ground stations available to downlink the data, plus duty cycle constraints. Under the continental strategy, the number of power cycles was reduced from 28.6 to 17.5 and the duty cycle usage was reduce from $15.1 \%$ to $14.4 \%$ while at the same time increasing the number of images acquired per day from 380 (70\% of opportunities) in 2012 to 438 (91\% of opportunities) in 2014/2015. The USGS continues to refine the continental strategy; since the winter of 2014 WRS-2 row 9 and above are no longer imaged with Landsat-7, permitting additional acquisitions in Africa and South Asia. 


\subsection{Landsat-8}

The Landsat-8 acquisition pre-launch requirement of 400 images per day was based on Landsat-7 capacity and was established prior to the no cost data policy. Even before launch it was apparent that Landsat-8 had capacity above 400 images per day. Following a February 11, 2013, launch Landsat-8 went into operations on May 30, 2013. Landsat-8 acquired 550 images per day through July 2014, at which time a study was initiated to increase the acquisitions until physical limits were approached. At 725 images per day most day-lit land descending images were acquired. To increase beyond 725 and to maintain a safe operating margin, additional ground station contacts would be needed to download the data. This daily limit of 725 was approved as the new operational limit.

In December 2014, the Landsat-8 LTAP was optimized for the 725 images/day limit. Three key changes were made:

(1) Between WRS-2 rows 20 and 105 (57 North and South Latitude) the amount of side lap is less than 50\%. Each point on the ground is revisited between 8 and 16 days. Scenes within these latitudes and all scenes over the U.S. are set as a high priority, which results in the acquisition of over $99 \%$ of the opportunities. Only maneuvers or calibration acquisitions will cause scenes to be rejected.

(2) High latitude scenes beyond the latitudinal bounds indicated in (1) have a priority ramp applied that is inversely proportional to the amount of side lap with adjacent scenes: the more side lap, the lower the priority. Each point on the ground is revisited between every 2 and 8 days. Even at high latitudes, over $92 \%$ of the scenes are acquired on average. During the Northern Hemisphere growing season, no scenes are currently rejected due to the daily limit.

(3) Many open water areas within closed basins and near-coastal scenes such as the Mediterranean Sea, Sea of Japan, and Indonesia are assigned a medium priority. These open water scenes have a $98 \%$ acquisition success rate. 


\subsection{Joint Acquisition Strategy}

The objective of the joint acquisition strategy is to take advantage of the strengths of each Landsat mission and to compensate for any known limitations. The Landsat-7 duty cycle constraints and the May 2003 SLC failure led USGS to focus on the large continental mid-latitude continental land masses. This collection strategy was aimed to extend the mission life of Landsat-7 through having fewer short, disjointed, collecting intervals that draw heavily on available power and duty cycles.

Landsat-8 provides superior capabilities for snow/ice and water imaging, due primarily to improved radiometric resolution and geolocation accuracy (e.g., Schott et al. 2015). Landsat-8 is achieving an 8-day revisit or better for scenes beyond $57^{\circ} \mathrm{N}$ and $\mathrm{S}$ latitude. The lack of duty cycle constraints also permits limited operational night imaging and higher priority imaging of islands. This lack of constraints also permits imaging of ascending day-lit land scenes in Antarctica and permits significant imaging of oceans for monitoring sea ice, oil seeps/spills and sea grasses. Landsat-8 is currently performing operational nighttime monitoring of the most active volcanoes worldwide. Landsat-7 and -8 are currently acquiring on average 1195 images/day. For continental land masses the Landsat mission is achieving effectively an 8 day revisit.

\section{Discussion}

\subsection{Acquisition lessons learned}

Ultimately, the depth and quality of the Landsat archive fuels sustainable resource management and global-scale scientific discovery and understanding. Landsat is now recognized as one of the most important U.S. Earth observation programs. A recent National Science and Technology Council (NSTC) assessment concluded that Landsat is the third most important U.S. observation system, behind Global Positioning System and Next Generation Weather Radar satellites (NSTC, 2014). The benefits of Landsat have an estimated annual value of nearly $\$ 1.8$ billion (Miller et al., 2013). 
The reasons for the importance of Landsat are numerous, and the addition of Landsat- 8 with higher quality data and its ability to add more than 700 images per day to the U.S. Landsat archive is one important factor. Landsat- 8 acquisitions extend the continuity of the global Landsat record and will be the foundation for many future studies. Additionally, new acquisitions are increasingly used within a time series that includes historical Landsat data. Without the LGAC, time series analysis and international and global-scale investigations would be stymied by major gaps in spatial and temporal coverage. Effectively, LGAC is the equivalent of a new mission. By ultimately adding nearly 5.5 million historical images to the archive, users worldwide now have greater access to the Landsat record than ever before, and the data now available are consistently orthorectified and calibrated with all other archived Landsat data.

LGAC will eventually become an historical footnote in the history of the Landsat program, an artifact of a different time with more limited capacities. Changes in Landsat- 8 and future mission technology now result in the addition of all daily acquisitions to the USGS EROS Center archive within hours after imaging. Notwithstanding, there are lessons from LGAC that can shape the future technical and programmatic foundation of the Landsat program. These lessons include:

1. Nothing is harder to image than the past. It is imperative that all Landsat observations are archived and made available to users. Past changes may be understood in quite different ways in the context of multi-decadal rather than decadal time series and with bi-weekly to seasonal repeat acquisitions rather than annual ones (Roy et al. 2014). It is imperative that future missions are designed to ensure that every sunlit scene is acquired to ensure continuity.

2. We cannot always anticipate future needs or capabilities. The founders of the Landsat Program deserve our praise and appreciation for having the foresight to collect data globally and to preserve all observations available. All the IC partners that made funding and planning decisions that allowed for the appropriate storage of their images holdings also merit appreciation. We continue to reap the benefits of efforts and wisdom of both of these communities. Whatever the decisions made, or the operational realities at play, improved processing techniques now allow us 
to benefit from access to the clear pixels in observations over predominantly cloudy areas. Future acquisition plans should generally proceed without undue concern about the cloudiness of places.

3. The ICs should be considered as partners and key contributors to global science. The ICs deserve our respect and appreciation for participating in LGAC. Their role in the future will likely evolve but they remain dedicated partners who represent an invaluable backup, reducing the risk of loss of Landsat observations. The ICs have now demonstrated the finest standards of open data sharing. The willingness of the ICs to participate in the LGAC process is a demonstrated international collaborative success and should serve as an example and a catalyst for a new era of global constellation imaging and open access.

The scientific value of LGAC is immeasurable and will continue to grow in importance, placing LGAC in the same light as the decisions to build and launch Landsats $1-8$, and to make all Landsat data available at no cost. As anticipated by Goward et al. (2006), over 5.5 million new images more than doubles the U.S. Landsat Archive holdings.

\subsection{Continuity and temporal revisit}

Satellites and sensors have a planned design life based on considerations including redundancy and quality of the parts and equipment used, orbit design, fuel use efficiency and the like. Since the 1970s improvements in mission design and management have seen average life expectancy increase from 3.3 to 8.6 years (Belward and Skøien 2015). Yet 14 years elapsed between the launches of Landsats 7 and 8. Landsat 5's extraordinary lifespan was testimony to high build quality and excellent mission management, but as aptly demonstrated by the catastrophic loss of Landsat 6, relying on an extended life expectancy is a strategy that puts continuity of measurements at considerable risk (Wulder et al. 2011). Continuity for the Landsat program is envisioned in terms of data products, with the goal of being able to use MSS, TM, ETM+, OLI, and future data streams in time series analyses, with minimal additional 
preprocessing required by the user (i.e., analysis-ready data) (Roy et al. 2014). The technical specifications for Landsat data have evolved over the years and will continue to do so, and continuity has not been strictly defined, leaving room for adjustments and improvements. Continuity has always been an implicit part of the program, but with recognition that Landsat is transitioning to an operational monitoring system, a more explicit characterization of what constitutes continuity is required.

At an abstract level, the concept of continuity suggests that new Landsat data must maintain the scientific integrity and objectivity of global land and climate change research established by previous Landsat systems, and thereby deliver the benefits to society for which the Landsat program was established. Society must continue to accrue the benefits from past Landsat investments by extending the long-term record, and the investments of agencies, organizations, and businesses that rely on Landsat data to meet their objectives must be protected. Continuity ensures the collection, archiving, and distribution of image data with the content, quality, and coverage needed to map, monitor, and assess the Earth's land and coastal environments and their responses to natural and human-induced changes over time.

More specifically, continuity requires long-term calibrated measurements that are consistent across the evolving instrument record. The record must continue to be uninterrupted, as it has been since the initiation of observations in 1972, with no significant temporal or geographic data gaps. Because the measurements must enable backward and forward assessments of the conditions and changes on the Earth's surface, measurements across the data record must have comparable spectral, spatial, temporal, and geographic properties that result in sufficiently consistent and accurate documentation of surface characteristic and dynamics.

Shortening the time between successive image acquisitions for many places is critical, which requires more frequent coverage than the 8-day, two-satellite configuration currently in place. This is especially true for cloudy places with short growing seasons, such as in high latitudes, for perpetually cloudy tropical forests, and for observing intra-annual vegetation phenology at spatial scales associated with human activity for crop monitoring and yield forecasting (Whitcraft et al. 2015; Kovalskyy and Roy, 2013; Cammalleri et al. 2013). Similarly, more frequent observations for evapotranspiration (ET) 
retrievals will dramatically improve monitoring of substantial variations in day-to-day ET rates caused by rapid vegetation growth in summer months, where vegetation amounts and ET rates can double over a ten-day period, and for when abrupt harvests, damaging weather events, and random irrigation wetting events occur. Other monitoring capabilities that would be greatly improved include inter-annual phenology changes associated with a changing climate (Melaas et al., 2013), tracking of glacier extent changes, and water use associated with water rights concerns. Regardless, the longstanding ad hoc requirement of 8-day repeat coverage is needed, and can be considered as a minimum, for time sensitive applications and for mitigation of frequent cloud cover.

In the short-term, increasing the temporal revisit time will only be possible by integrating Landsat data with data from other sensors that could be considered as providing Landsat-like data (Wulder and Coops 2014), such as Sentinel-2 (Drusch et al. 2012), which was successfully launched June 23, 2015 . Although Sentinel-2 cannot be considered a replacement or alternative for Landsat, it does offer a promising augmentation to the Landsat program. While variable by latitude (Wulder et al., 2015), with two Landsat satellites in 16-day orbits and 8-day repeat, and two Sentinel-2s in orbit with a combined five-day repeat cycle, there will be $10 \mathrm{~m}$ to $30 \mathrm{~m}$ multi-spectral global coverage every $2-4$ days. The latitudinal difference in revisit is due to the increasing overlap between imaging footprints on successive orbits away from the equator and toward the poles (Wulder et al. 2015).

Sentinel-2 multispectral capabilities are generally consistent with those of Landsat (Drusch et al. 2012; Irons et al. 2012; Wulder et al. 2015), but there are some important differences and cautions to note that may affect some longstanding Landsat applications. Sentinel-2 has no thermal imaging, which has typically been required for reliable cloud detection and ET monitoring. It is important to note that recent research has shown the value of the Landsat- 8 cirrus band for cloud screening, with simulated Sentinel-2 data producing similar outcomes to those of Landsat- 8 when tested in a cloud detection and masking application (Zhu et al. 2015). Clearly, cloud screening will be better for Sentinel-2 than it would be if it did not have a cirrus band, but the lack of a thermal band will undermine cloud detection in many situations. Greater swath width is another important difference, because the increased angular views 
(20.6 $6^{\circ}$ for Sentinel-2 vs. $15^{\circ}$ for Landsat-8) result in both a larger area being sensed and an increase in surface reflectance anisotropic effects. Although the latter may be correctable to some extent, a priori information on surface anisotropy may be required. In addition, the capacity to robustly integrate measures from Landsat and Sentinel-2 must be verified once both datasets are available over common areas. Finally, incorporating Sentinel-2 data into the global archive will have serious implications for the Landsat data storage and delivery system. Each day of Sentinel-2 data collection will result in 1.6 TB of imagery, for each satellite, in comparison to 750 GB per day for Landsat-8, 260 GB for Landsat-7, and, for historical reference, 40 GB for Landsat-5 (Wulder et al. 2008).

\subsection{Looking forward: Sustainable Land Imaging}

Prior to Landsat-8, Landsat satellites were launched as either experimental or stopgap systems designed to maintain a unique and highly valuable set of Earth system measurements that commenced in 1972 (Figure 8). With the development of Landsat-8, a shift towards an operational program began. The associated strategy, based on the concept of data continuity to link Landsat-8 (and beyond) to past sensor systems was embedded in the name of the system before launch: the Landsat Data Continuity Mission. By naming the primary sensor on the new system the Operational Land Imager, the U.S. government confirms the critical role of Landsat for continuous Earth system observations into the future. In the spirit of continuity, consolidation of data from all holdings enhances the availability and use of historic data by processing consolidated data to the same standards as prior data in the U.S. archive.

The clear societal value of the Landsat archive has led to a new programmatic commitment to data continuity (see NSTC, 2014; Miller et al. 2013). Since 2014, the U.S. has pursued a Sustainable Land Imaging (SLI) program as an interagency partnership between NASA and USGS in order to secure Landsat continuity over the next decades. The focus on long-term planning represents a shift from previous "single mission" approaches to Landsat and a recognition that Landsat data should be provided for the foreseeable future to support operational applications (Figure 8). 
Current forecasts suggest that Landsat-7 could have sufficient fuel to last until at least 2020. Assuming no other technical failures on the operating Landsat platforms, this suggests the possibility of a gap in 8-day coverage during the $2020-2022$ period, when only Landsat-8 will be operating (given a Landsat-9 launch in 2023). To minimize this gap, investigations are underway to extend the life of Landsat- 7 by changing the orbit altitude and allowing an earlier equatorial crossing time; such an alteration to the decommissioning strategy could result in a 2022 end of life.

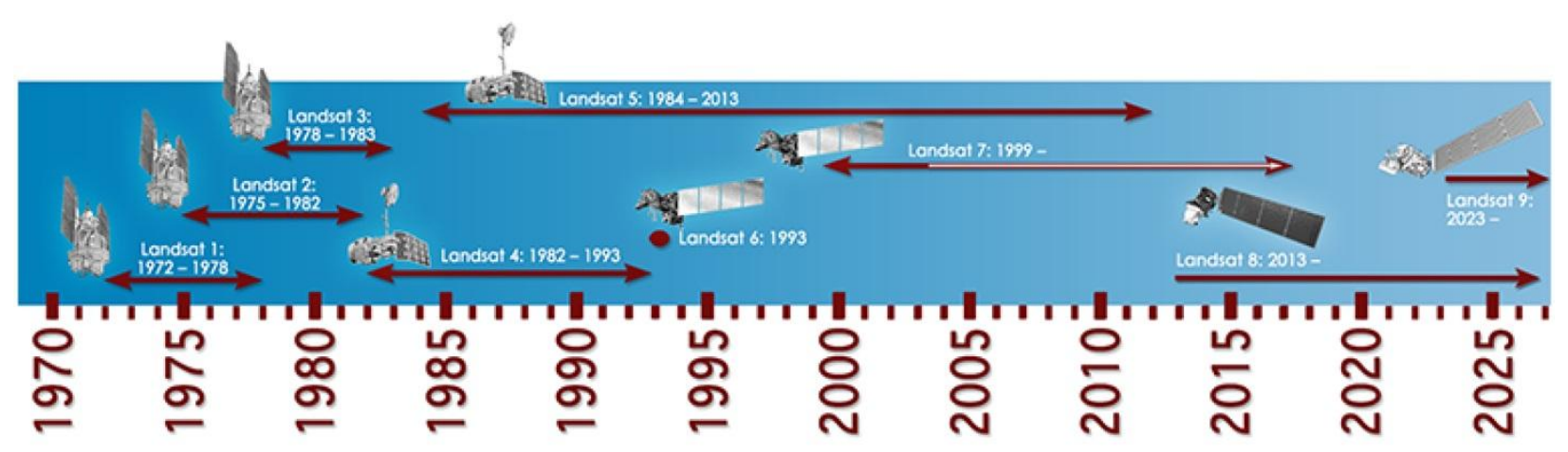

Figure 8. Graphical history of the past and planned Landsat series of satellites (Source: NASA).

While the mission requirements for Landsat-9 are well defined, the capabilities of future missions such as Landsat-10 and beyond are still evolving. The USGS/NASA Landsat Science Team was recently asked to prioritize future systems enhancements for Landsat. Increasing the temporal revisit frequency, either via a wider imaging swath or via more on-orbit platforms, was considered the highest priority. This reflects both interest in seasonal land dynamics, including vegetation phenology, cropping patterns, and water resources (e.g. Zhu et al., 2012; Melaas et al., 2013; Anderson et al., 2012), as well as the importance of collecting more frequent imagery to mitigate cloud contamination at the time of Landsat overpass (Kovalskyy and Roy 2015; Whitcraft et al., 2015). Other potential enhancements include separate $15 \mathrm{~m}$ visible and near-infrared bands to support improved spatial resolution for NDVI products, and additional spectral bands in the red-edge and shortwave-infrared region for active fire detection and water vapour retrieval. Finally, consideration was also given to migrating the Landsat observatory to a hyperspectral capability to improve ecological applications of Landsat. The next 5-6 years will see an 
ongoing discussion within the NASA and USGS science communities to fully define the capabilities of Landsat in the late 2020s and beyond.

\section{Conclusions}

The current status of the LGAC program to produce a single consolidated archive of all Landsat data has been described. As of January 1, 2015 there were over 5.5 million images in the USGS archive. The LGAC was initiated in 2010 and since then has resulted in the contribution of approximately 3.2 million of these images, equivalent to two Landsat-5 missions. An additional 2.3 million images have been identified and could be added in the coming years, and are expected to be augmented by additional identified images not previously accounted for. The increased data holdings, combined with systematic Landsat processing and free data access will provide improved opportunities for local to global spatial scale, multi-decadal Landsat-based applications and science. The greatly expanded archive content provided through LGAC and the ICs, with its greatly improved geographic and temporal distribution guarantees that applications and insights enabled by Landsat data will continue to proliferate.

The shared importance of both space- and ground-segments in capturing and disseminating image data in a timely and analysis-ready form has been highlighted over the life of the Landsat program. The synergy between the space- and ground-segments as implemented for Landsat- 8 has certainly demonstrated that lessons have been learned and implemented. The early years of the Landsat program reflect the logistical and computing limitations present at that time. The collection, downlink, and storage of so many images by so many individual ICs is remarkable and demonstrates that a true understanding of the value of the imagery was known to those involved. This knowledge of the value of the imagery collected also relates to the generally altruistic enthusiasm for ensuring that the independent IC image holdings were shared or transferred to the USGS. It is difficult to overstate the importance of the LGAC initiative, as it will eventually add over 5.5 million images to the archive, for a total of about 7.5 million combined images, which will add to the current and growing OLI and ETM+ collections. As of January 1, 2015, well over half (57\%) of the images in the archive are there as a result of the LGAC initiative. An 
undeniable case has been made for the wisdom of the initiation, and the need for continuation until completion, of the LGAC initiative. Looking forward, the need for continuity implies a need for more operational terrestrial image data collection programs as well as opportunities for increased flexibility and integration across complementary sources of image data, from both commercial and government agencies.

\section{Acknowledgments}

This communication has been made possible and enriched by the on-going discussions and deliberations of the USGS / NASA Landsat Science Team (https://landsat.usgs.gov/science_Landsat_Science_Team.php). The participation of Wulder and White was supported as part of the "National Terrestrial Ecosystem Monitoring System (NTEMS): Timely and detailed national cross-sector monitoring for Canada" project jointly funded by the Canadian Space Agency (CSA) Government Related Initiatives Program (GRIP) and the Canadian Forest Service (CFS) of Natural Resources Canada. We greatly appreciate the time committed and the insightful comments made by three anonymous reviewers that helped us to improve the manuscript.

\section{References}

Anderson, M.C., Allen, R.G., Morse, A. and Kustas, W.P. 2012. Use of Landsat thermal imagery in monitoring evapotranspiration and managing water resources. Remote Sensing of Environment. 122: $50-65$

Arvidson, T., Gasch, J., and Goward, S. N. 2001. Landsat 7's long-term acquisition plan-An innovative approach to building a global imagery archive. Remote Sensing of Environment, 78, 13-26

Arvidson, T., Goward, S.N., Gasch, J., and Williams, D. 2006. Landsat-7 long-term acquisition plan: Development and validation. Photogrammetric Engineering and Remote Sensing. 72: 1137-1146 
Belward, A.S. and Skøien, J. O. 2015. Who launched what, when and why; trends in Global Land-Cover Observation capacity from civilian Earth Observation satellites, ISPRS Journal of Photogrammetry and Remote Sensing, 103, 115-128

Bolden, C.F. 2015. Statement of The Honorable Charles F. Bolden, Jr. Administrator, National Aeronautics and Space Administration before the Subcommittee on Commerce, Justice, Science, and Related Agencies Committee on Appropriations, U. S. House of Representatives 4th March 2015. www.hq.nasa.gov/legislative/hearings/3-4-2015_BOLDEN.pdf (accessed 30th April 2015)

Brooks, E.B., Wynne, R.H., Thomas, V.A., Blinn, C.E., and Coulston, J.W. 2014, On-the-fly massively multitemporal change detection using statistical quality control charts and Landsat data. IEEE Transactions on Geoscience and Remote Sensing. 52, 3316 - 3332

Cammalleri, C., Anderson, M.C., Gao, F., Hain, C.R., and Kustas, W. P. 2013. A data fusion approach for mapping daily evapotranspiration at field scale. Water Resources Research. 49 (8), 4672-4686

Chander, G., Helder, D.L., Malla, R., Micijevic, E., and Mettler, C.J. 2007. Consistency of L4 TM absolute calibration with respect to the L5 TM sensor based on near-simultaneous image acquisition. J. Butler, \& J. Xiong (Eds.), Proceedings of SPIE Conference on Earth Observing Systems XII in San Diego, CA. 6677, (p. 66770F).

Cohen, W. B., and Goward, S. N., 2004, Landsat's role in ecological applications of remote sensing. Bioscience, 54(6), 535-545.

Draeger, W.C., T.M. Holm, D.T. Lauer, and R.J. Thompson, 1997. The availability of Landsat data: Past, present and future, Photogrammetric Engineering \& Remote Sensing, 63(7): 869-875.

Drusch, M., Del Bello, U., Carlier, S., Colin, O., Fernandez, V., Gascon, F., Hoersch, B., Isola, C., Laberinti, P., Martimort, P., Meygret, A., Spoto, F., Sy, O., Marchese, F., Bargellini, P. (2012), Sentinel-2: ESA's Optical High-Resolution Mission for GMES Operational Services, Remote Sensing of Environment. 120, 25-36.

Foust, J. 2015. White house proposes \$18.5 billion budget for NASA. Space News. Feb. 2, 2015. 
Gong, P., Wang, J., Yu, L., Zhao, Y., Zhao, Y. Liang, L., Niu, Z., Huang, X., Fu, H., Liu, S., Li, C., Li, X., Fu, W., Liu, C., Xu, Y., Wang, X., Cheng, Q., Hu, L., Yao, W., Zhang, H., Zhu, P., Zhao, Z., Zhang, H., Zheng, Y., Ji, L., Zhang, Y., Chen, H., Yan, A., Guo, J., Yu, L., Wang, L., Liu, X., Shi, T., Zhu, M., Chen, Y., Yang, G., Tang, P., Xu, B., Giri, C., Clinton, N., Zhu, Z., Chen, J. and Chen, J., 2013, Finer resolution observation and monitoring of global land cover: first mapping results with Landsat TM and ETM+ data, International Journal of Remote Sensing, 34 (7), 2607-2654

Goward, S., Faundeen, J., Arvidson, T., Irons, J.R., Williams, D., and Franks, S. 2006. Historical Record of Landsat Global Coverage: Mission Operations, NSLRSDA, and International Cooperator Stations. Photogrammetric Engineering \& Remote Sensing 72, 1155-1169

Gutman, G., Byrnes, R., Masek, J., Covington, S., Justice, C., Franks, S., and Headley, R. 2008. Towards Monitoring Land-Cover and Land-Use Changes at a Global Scale: The Global Land Survey 2005. Photogrammetric Engineering \& Remote Sensing. 74: 6-10

Gutman, G., Huang, C., Chander, G., Noojipady, P., and Masek, J. G. 2013. Assessment of the NASA USGS Global Land Survey (GLS) datasets. Remote Sensing of Environment. 134: 249-265

Hansen, M. C. and Loveland, T. R. 2012. A review of large area monitoring of land cover change using Landsat data. Remote Sensing of Environment. 122: 66-74

Hansen, M. C., Potapov, P. V., Moore, R., Hancher, M., Turubanova, S. A., Tyukavina, Thau, D., Stehman, S. V., Goetz, S. J., Loveland, T. R., Kommareddy, A., Egorov, A., Chini, L., Justice, C.O., and Townshend J.R.G., 2013, High-resolution global maps of 21st-century forest cover change. Science, 342(6160): 850-853

Hermosilla, T., Wulder, M. A., White, J. C., Coops, N.C., Hobart, G. 2015. An integrated Landsat time series protocol for change detection and generation of annual gap-free surface reflectance composites. Remote Sensing of Environment. 158: 220-234

Irons, J. R.; Dwyer, J. L., and Barsi, J. A. 2012. The next Landsat satellite: The Landsat Data Continuity Mission. Remote Sensing of Environment. 122: 11-21 
Kennedy, R.E., Andrefouet, S., Cohen, W.B., Gomez, C., Griffiths, P., Hais, M., Healey, S.P., Helmer, E.H., Hostert, P., Lyons, M.B., Meigs, G.W., Pflugmacher, D., Phinn, S.R., Powell, S.L., Scarth, P., Sen, S., Schroeder, T.A., Schneider, A., Sonnenschein, R., Vogelmann, J.E., Wulder, M.A, and Zhu, Z. 2014. Bringing an ecological view of change to Landsat-based remote sensing. Frontiers in Ecology and the Environment. 12(6): 339-346

Kovalskyy, V. and Roy, D.P. 2013. The global availability of Landsat 5 TM and Landsat 7 ETM+ land surface observations and implications for global 30m Landsat data product generation, Remote Sensing of Environment, 130, 280-293

Kovalskyy, V. and Roy, D. 2015. A one year Landsat 8 conterminous United States study of cirrus and non-cirrus clouds. Remote Sensing. 7(1): 564-578

Loveland, T. R., and Dwyer, J. L. 2012. Landsat: Building a strong future. Remote Sensing of Environment, 122, 22-29

Loveland, T.R., Irons, J.R., and C.E. Woodcock. 2007a. Landsat Science Team meeting summary. The Earth Observer 19(2): 10-14

Loveland, T.R., Irons, J.R., and Woodcock, C.E. 2007b. Landsat Science Team meeting summary. The Earth Observer 19(5): 36-41.

Loveland, T.R., Irons, J.R., and Woodcock, C.E. 2008. Landsat Science Team meeting summary. The Earth Observer 20(2): 35-40

Markham, B.L., and Helder, D.L. 2012. Forty-year calibrated record of earth-reflected radiance from Landsat: A review. Remote Sensing of Environment, 122, 30-40

Markham, B.L., Storey, J.C., Williams, D.L. and Irons, J.R. (2004). Landsat sensor performance: history and current status. IEEE Transactions on Geoscience and Remote Sensing. 42(12), 2691-2694

Melaas, E.K, M.A. Friedl, and Z. Zhu (2013), Detecting interannual variation in deciduous broadleaf forests phenology using Landsat TM/ETM+ data, Remote Sensing of Environment, 132, 176-185. 
Miller, H.M., Richardson, L., Koontz, S.R., Loomis, J., and Koontz, L. 2013. Users, uses, and value of Landsat satellite imagery-Results from the 2012 survey of users: U.S. Geological Survey OpenFile Report 2013-1269, 51 p., http://dx.doi.org/10.3133/ofr20131269.

NSTC (National Science and Technology Council), 2014. National Plan for Civil Earth Observations. Washington, D.C., Executive Office of the President, $71 \quad$ p., https://www.whitehouse.gov/sites/default/files/microsites/ostp/NSTC/national_plan_for_civil_earth _observations_-_july_2014.pdf

Pecora, W.T. 1966. Earth Resources Observation Satellite (EROS): A Department of Interior Program to Utilize Space-acquired Data for Natural and Human Resource Management, U.S. Department of Interior, U.S. Geological Survey, Washington D.C., 20 p.

Roy, D.P., Ju, J., Kline, K., Scaramuzza, P.L., Kovalskyy, V., Hansen, M.C., Loveland, T.R., Vermote, E.F., Zhang, C., 2010, Web-enabled Landsat Data (WELD): Landsat ETM+ Composited Mosaics of the Conterminous United States, Remote Sensing of Environment, 114: 35-49

Roy, D.P., Wulder, M.A., Loveland, T.R., Woodcock, C.E., Allen, R.G., Anderson, M.C., Helder, D., Irons, J.R., Johnson, D.M., Kennedy, R., Scambos, T.A., Schaaf, C. B., Schott, J.R., Sheng, Y., Vermote, E.F., Belward, A.S., Bindschadler, R., Cohen, W.B., Gao, F., Hipple, J.D., Hostert, P., Huntington, J., Justice, C.O., Kilic, A., Kovalskyy, V., Lee, Z. P., Lymburner, L., Masek, J.G., McCorkel, J., Shuai, Y., Trezza, R., Vogelmann, J., Wynne, R.H., Zhu, Z. 2014. Landsat-8: science and product vision for terrestrial global change research, Remote Sensing of Environment, 145, 154 172

Schott, J., Gerace, A., Woodcock C.E., Wang, S., Zhu, Z., and Wynne, R.H., 2015. The Impact of improved signal to noise ratios on algorithm performance: Case studies for Landsat class instruments, submitted to Remote Sensing of Environment (this issue).

Townshend, J. R. G. and Justice, C. O., 1988, Selecting the spatial-resolution of satellite sensors required for global monitoring of land transformations. International Journal of Remote Sensing, 9, 187-236 
Whitcraft, A., Becker-Reshef, I., and Justice, C. 2015. A Framework for Defining Spatially Explicit Earth Observation Requirements for a Global Agricultural Monitoring Initiative (GEOGLAM). Remote Sensing. 7(2): 1461-1481

Woodcock, C.E., Allen, R.G., Anderson, M., Belward, A., Bindschadler, R., Cohen, W.B., Gao, F., Goward, S.N., Helder, D.L., Helmer, E.H., Nemani, R., Oreopoulos, L., Schott, J.R., Thenkabail, P.S., Vermote, E.F., Vogelmann, J.E., Wulder, M.A., and Wynne, R., 2008, Free access to Landsat imagery: Science, 320, (5879), 1011

Wulder, M.A., White, J.C., Goward, S.N., Masek, J.G., Irons, J.R., Herold, M., Cohen, W.B., Loveland, T.R., and Woodcock, C.E. 2008. Landsat continuity: Issues and opportunities for land cover monitoring. Remote Sensing of Environment. 112: 955-969

Wulder, M.A., White, J.C., Masek, J.G., Dwyer, J., and Roy, D.P. 2011. Continuity of Landsat observations: Short term considerations. Remote Sensing of Environment. 115: 747-751

Wulder, M.A., Masek, J.G., Cohen, W.B., Loveland, T.R., and Woodcock, C.E., 2012. Opening the archive: how free data has enabled the science and monitoring promise of Landsat. Remote Sensing of Environment 122: 2-10

Wulder, M.A. and N.C. Coops. 2014. Make Earth observations open access. Nature. 513(7516): 30-31

Wulder, M.A., T. Hilker, J.C. White, N.C. Coops, J.G. Masek, D. Pflugmacher, and Y. Crevier. 2015. Virtual constellations for global terrestrial monitoring. Remote Sensing of Environment. 170: 62-76

Zhu, Z., Woodcock, C.E., and Olofsson, P. 2012. Continuous monitoring of forest disturbance using all available Landsat imagery. Remote Sensing of Environment. 122: 75-91

Zhu, Z., and Woodcock, C.E. 2014. Continuous change detection and classification of land cover using all available Landsat data. Remote Sensing of Environment. 144: 152-171

Zhu, Z., Wang, S., and Woodcock, C.E. 2015. Improvement and expansion of the Fmask algorithm: cloud, cloud shadow, and snow detection for Landsats 4-7, 8, and Sentinel 2 images. Remote Sensing of Environment. 159: 269-277 


\section{List of Figure Captions}

Figure 1. USGS Landsat archive holdings as of January 1, 2015.

Figure 2. Key International Cooperators (ICs) and International Ground Stations (IGS) with notable holdings of Landsat images unique to the archive (After USGS: http://landsat.usgs.gov//about_ground_stations.php). See Table 2 for the key to station IDs.

Figure 3. What the status of the USGS archive holdings would have been as of January 1, 2015 without LGAC.

Figure 4. Location and number of images that have been added to the USGS archive holdings via the LGAC as of January 1, 2015.

Figure 5. Potential future state of the archive if all anticipated LGAC holdings (shown in Figure 6) are incorporated.

Figure 6. Location and number of images identified through LGAC that remain to be added to the archive.

Figure 7. Temporal distribution of USGS Landsat archive holdings before (left) and after (right) LGAC, by 10-year epochs. Note that the 2000 epoch includes images acquired from 2000 to 2014 .

Figure 8. Graphical history of the past and planned Landsat series of satellites (Source: NASA). 